\section{SCIENTIFIC FRAUD}

\section{False accusations at London hospital}

\section{London}

FALSE accusations of fraud have been levelled at a British medical scientist at a London teaching hospital, apparently in an attempt to damage his reputation. The person accused (whose name is being deliberately withheld) holds appointments as a lecturer at the Royal Postgraduate Medical School (RPMS) and as a registrar at the Hammersmith Hospital, London, where the school is based.

One bizarre feature of the case is that letters to the school and to the Wellcome Trust, from which the scientist is seeking a scholarship, said that Nature had been conducting an investigation of several improprieties, including the forging of references in an application for registration to the General Medical Council and plagiarism of the work of other researchers in scientific papers submitted for publication. The letters are signed "John Dickson, for the Vanguard Detective Agency", and are constructed so as to suggest that the detective agency is employed in the investigation.

But in a letter to Nature, "John Dickson, PhD" merely suggests that an investigation should be carried out on the basis of the same and further allegations, including collusion with a travel agent to convert overseas travel funds into cash. There is no record of Vanguard Detective Agency, but the address in suburban west London from which the letters were sent is adjacent to an engineering workshop labelled "Vanguard Engineering Company".

Further allegations include the assertion that the accused scientist may have "fraudulently obtained his medical degree, that he was dismissed from a PhD course at Brunel University and that "the testimony of his fellow-workers" reveals that his conduct as a scientist is unethical. But the records office at Brunel University says there is no record of the accused scientist ever having been a student there.

Officials of the RPMS say they have the highest regard for the person accused, believing that he is at the start of a distinguished career. A senior member of the staff there says he has known the person's family for 30 years, and that the letters concerned must be a cruel hoax.

In the event, the author of the letter appears to be somebody who also holds an appointment at the Hammersmith Hospital. Earlier this week, he was under pressure to resign. An official of the Wellcome Trust said that the accusing letter might have been taken seriously, "and we might have found ourselves writing an unfortunate letter", had it not been for the "fishy" coincidence that the address given for the Vanguard Detective Agency is in the street in which the accused scientist lives.

Ben Webb

\title{
Battle over value of words
}

\section{Washington}

THE law courts of France, West Germany, Switzerland and the United States will provide the unlikely setting next year for a battle between two US publishers over the value for money offered by scholarly journals in physics. The battle began with a survey of the cost-effectiveness of physics journals published in the Bulletin of the American Physical Society and, in shortened form, in Physics Today. The commercial publisher Gordon and Breach, which emerged as the least costeffective of those surveyed, claims that Henry Barschall, the author of the survey, was biased and the methodology was flawed. It is taking legal action against the American Physical Society (APS) and the American Institute of Physics (AIP) the parent organizations of the two journals which published the survey - and against Barschall, in European countries where relevant laws are strict.

Barschall, a retired professor of physics at the University of Wisconsin in Madison, was prompted to examine the value for money of physics journals because their rising costs were forcing the university physics library to cancel subscriptions (see this issue page 349). He surveyed more than 200 physics journals, rating them according to cost and impact. Journals of both the APS and the AIP emerge among the most cost-effective.

Barschall measured cost-effectiveness as the ratio of the cost per printed character of a journal to the frequency with which it is cited, and found dramatic variations in the results. In the field of condensedmatter physics, for example, he reports that the cost-effectiveness varies by a factor of 200. "All the publishers whose journals have low average costs per character or low ratios of cost to impact are scientific societies or associations, while the publishers whose journals have high costs per character or high ratios of cost to impact are commercial firms." Barschall concludes that a solution to the present financial "crisis" in libraries caused by increasing costs of journals might be for authors to publish their papers in journals with low cost per character. In the survey, Gordon and Breach had the highest average ratio of cost to impact: 29.5 compared to 0.28 for the APS and 1.1 for the AIP, one of its member societies.

The lawyer representing Gordon and Breach in Switzerland, Alfred Gilgan, says this gives the impression that Gordon and Breach is a company of "crooks who are extorting their subscribers". The company has filed suits against APS, AIP and Barschall, seeking retraction, damages and an injunction preventing further articles comparing the physics journals of both publishers until the dispute is resolved. AIP offered to settle the dispute by publishing a response from Gordon and Breach in Physics Today, but this was rejected because the response was to be published along with a letter from Barschall.

Gilgan maintains that the article in Physics Today is a "disguised" advertisement for AIP and APS. "Barschall is not an independent scientist who conducted a survey in the interest of the science community", he says, claiming that Barschall is biased because of his links with AIP. For two years before he wrote the article, he was on the governing board of AIP. When he wrote the article, Barschall was still a member of the publishing policy committee of AIP, as was declared in a footnote to the article. Barschall denies the accusations of bias, saying that APS and AIP "had nothing to do with" the survey, and that he had no financial links with AIP or APS.

Gilgan also accuses Barschall of making "outrageous errors" in his calculations and using "misleading" methodology. The cost-per-character measure is too simplistic and "unjustly prejudices journals with a high content of formulae, graphs and charts", he says. Richard Meserve, one of the lawyers for AIP in the United States, disputes the claims, but admits that any method "is necessarily going to be imperfect". But Gilgan also argues that the costs calculated by Barschall for the Gordon and Breach journals were between 10 and 50 per cent too high, and accuses Barschall of choosing to survey the most expensive journals published by Gordon and Breach.

The measurement of 'impact' by a citations score is also criticized by Gilgan as a measure only of the circulation figure of a journal, not of its value to a subscriber. Highly specialized journals, such as those published by Gordon and Breach, have smaller circulation figures and thus higher production costs and subscription prices, he says, than general physics journals such as those of AIP. But "the characters that are actually useful to the subscriber are cheaper at Gordon and Breach than at AIP", he claims.

Barschall says that he used "standard" methodology and that he did not claim it was "the sole determinant as to what is a useful journal"; he wrote the article "from the point of view of a librarian" and "librarians need to know how much they have to pay to get a page of a journal". $\mathrm{He}$ also disputes that the journals of Gordon and Breach are more specialized than those of AIP and APS and that he selected those which are the most expensive. $\mathrm{He}$ surveyed, he says, all the physics journals to which he had "easy access" in the library.

Christine McGourty

NATURE · VOL $341 \cdot 28$ SEPTEMBER 1989 